\title{
A Pedagogic Strategy for Instructors of Post- Secondary Sector Students Returning to Learn from Concussion
}

\author{
Gail Frost, Maureen Connolly \\ Brock University
}

Concussion is a functional brain injury that can produce physical, cognitive, emotional and sleep-related symptoms. Return to learn protocols designed to help students recovering from concussion recommend a gradual, symptom-governed, increase in cognitive activity before a return to full-time school attendance and participation. Return to learn in a post-secondary setting often means that instructors are tasked with accommodating for these students, some of whom are back in the classroom even though they are still experiencing symptoms. This paper presents a progressive, ramping approach to increasing cognitive load by using literal, interpretive and applied adaptations to already existing course requirements, with the goal of minimizing the risk of provoking or worsening post-concussion symptoms.

Les commotions cérébrales sont des lésions fonctionnelles au cerveau qui peuvent provoquer des symptômes physiques, cognitifs et émotionnels ainsi que des troubles du sommeil. Selon le protocole de reprise des études conçu pour aider les étudiants qui se remettent d'une commotion, on recommande une augmentation graduelle de l'activité cognitive, en fonction des symptômes, avant d'effectuer un retour aux études à temps plein. Dans les établissements postsecondaires, on demande souvent aux instructeurs de mettre en place des mesures d'adaptation pour ces étudiants qui, dans certains cas, éprouvent encore des symptômes lorsqu'ils retournent en classe. Cet article présente une approche progressive visant à augmenter petit à petit la charge cognitive au moyen d'aménagements - d'ordre littéral, interprétatif et appliqué - apportés aux exigences de cours existantes, de manière à minimiser le risque de déclencher ou d'aggraver le syndrome post-commotion cérébrale.

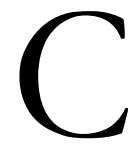

oncussion is a functional brain injury caused by an impact force that can produce physical, cognitive, emotional and sleeprelated symptoms. While many concussions resolve within four weeks if managed correctly, some individuals are left with lingering symptoms that may have measurable effects on academic performance, including decreased learning and memory, decreased attention, and slowed processing speed and reaction time (Henry, Elbin, Collins, Marchetti, \& Kontos, 2016; Keightley et al., 2014; Sady, Vaughn, \& Gioia,
2011). We are seeing more students in our classes who have been diagnosed with this injury, thanks in part to better concussion education programs and recognition tools. These students are not just athletes, as falls and motor vehicle accidents also account for many concussions (CDC, 2019). Some are not ready to take up their pre-injury academic load but are afraid of falling behind if they do not return to class as soon as possible, with or without a doctor's clearance. A graduated return-to-learn strategy has been devised to promote a successful 
return to the classroom for elementary and high school students (McCrory et al., 2017). However, it is difficult to implement in a post-secondary setting, as it requires extensive parental and school involvement and coordination. While some help may be available to post-secondary students through campus wellness centres, more often it is the individual course instructor who is given the responsibility of helping the student with concussion symptoms that may resolve in a relatively brief time period. The expectation is that they will make accommodations for the student by adjusting course content and assessments to account for the symptoms that make academic tasks difficult. In Ontario, accommodations for learning are legally mandated unless they present 'undue hardship' (Ontario Human Rights Commission, 2019). At our university, information given to instructors of students who have sustained a concussion encourages strategies like providing the student with class notes, allowing frequent breaks, extending deadlines for completion of assignments and missed tests, and creating alternate assignments.

This can be a frustrating process for both instructor and student, partly due to the nature of postconcussion symptoms, which can appear immediately after the injury-causing impact or several hours later and can last for days, weeks, or in some cases, even longer. Because concussion is an upset of function and not a result of structural damage to the brain, it is not detectable with commonly used clinical imaging techniques such as computed tomography (CT) scan and magnetic resonance imaging (MRI). The appearance and disappearance of symptoms is important in both diagnosis of concussion and monitoring of recovery. These symptoms include sensitivity to light and noise, dizziness and nausea, headache, fatigue, blurred vision, difficulty concentrating and remembering, confusion, feeling slowed down or 'in a fog', sleep difficulties and emotional changes ("An educator's guide to concussions in the classroom", 2018). The specific symptoms which arise can vary widely between individuals. They are thought to be the result of a cascade of neurochemical changes in the brain, triggered by the impact force, which result in impaired connectivity, changes in neurotransmission, reduced cerebral blood flow, altered glucose metabolism and what has been described in simpler terms as an "energy crisis" (Barkhoudarian, Hovda, \& Giza, 2011). The additional neurometabolic cost of physical or cognitive activity undertaken while the brain is trying to re-establish normal functioning is a source of stress that can make symptoms worse (Sady et al., 2011; Valovich McLeod \& Gioia, 2010). In addition, pre-existing conditions such as anxiety, depression or a learning disability have been shown to prolong the recovery period after concussion (Hutchinson, Comper, Csenge, \& Richards, 2014).

Current best practices suggest that, after a brief period of rest (24-48 hours), individuals can become gradually more cognitively and physically active while staying below the threshold levels at which symptoms become worse (McCrory et al., 2017). A simple plan for implementing this with cognitive activity is: if an increase in cognitive demand produces no change in symptoms then the student may continue with the work. If symptoms increase or worsen, then discontinue the activity and rest for 20 minutes. If symptoms improve with 20 minutes rest, the activity can be re-started at or below the previous level. If the symptoms do not improve with 20 minutes of rest, then discontinue the activity and start again when symptoms have decreased, such as the next day ("An educator's guide to concussions in the classroom", 2018). Many students tend to underestimate the severity of symptoms and how easily they can be exacerbated by cognitive or physical activity, especially if it is their first concussion. In this situation, applying more effort to a task is not only unhelpful, it may be detrimental. However, concern about falling behind in classes and staying on schedule to graduate can push students to try too hard in the initial stages of recovery.

The process of accommodation can include strategies to deal with the challenges created by physical teaching spaces, online teaching spaces, and 
course organization. Consider addressing as many of these as is practical before looking at ways to adjust the student's assignments and projects. By looking at, and optimizing, things like classroom lighting and noise levels, where the student sits and when they can take breaks, how your material is presented and made available in the classroom and online, and what peer support can be enlisted, you will have decreased some of the issues that create cognitive stress before the student begins the course work you are expecting them to attempt and complete (Frost \& Connolly, 2018).

The course work that awaits the student will likely involve a variety of levels of pace and sophistication relating to content, process, conceptual work, group work, online work, reading, and writing. The student will want to get back into the swing of the course and pick up where they left off. The instructor wants this as well. Yet, this cannot happen because the student's brain, mind, nervous system, and cognitive processing cannot simply return and pick up where they left off. The instructor, along with their student, must progress back into the many complex and intertwined elements of the course. This progression must be just that: progressive. It must begin with simpler cognitive tasks: knowledge-based, literallevel tasks that do not require comprehension, application, analysis, synthesis, or evaluation - the type of tasks using verbs like identify, locate, label, select, list, name, record and repeat ("Bloom's taxonomy verb wheel", 2018). This type of cognitive task allows the student to re-engage with the subject matter and re-connect with the course assignments in a way that is commensurate with their level of cognitive functioning and focus. Then, the student could move on to more complex cognitive work and more complex tasks, tasks that require comprehension, interpretation and application.

To develop a system of progression that is grounded in curricular development and alignment, we turned to the work of Paulo Freire, a literacy educator and theorist who proposed linkages between peoples' life conditions and appropriate forms of learning activities (Freire, 1972). While Freire's primary motivation was to interrupt the structures of power that kept poor people from becoming literate and using all the social and cultural benefits that follow from critical literacy, his ideas about relevant and progressively appropriate learning tasks have much cogency for our own project.

Freire's model of an archeology of consciousness (Finlay \& Faith, 1987) combined with Zimmet's (1987) propositions regarding learning levels are frequently applied in the service of analysis and critique of curriculum and schooling at all levels. In this instance, we apply them for their fundamentally pedagogic benefits to assist instructors in postsecondary contexts who are engaging in adapting their course elements for students in their classes who are returning to learn after concussion. Freire proposes naïve, superstitious and critical as forms of consciousness that indicate degrees and kinds of agency and autonomy related to subject matter and the expression of its comprehension. Zimmet operationalizes these forms of consciousness into literal, interpretive and applied engagements with reading and learning. It is our intention to support students returning from concussion as they re-engage with course material at a meta-cognitive level. However, this cannot be achieved in an instantaneous eidetic re-capturing of their preconcussion relationship with the subject matter in the course. We propose a progressive sequence of literal, interpretive, and applied adaptations to already existing course requirements to create the gradual ramping necessary to avoid exacerbating the neurometabolic cascade that both underlies and accompanies concussion and provoking or worsening post-concussion symptoms. We are especially attentive to the online environment as well as the theoretical, technical and practical expectations of instructors in post-secondary contexts.

As this paper unfolds, we will lead the reader through a series of examples of literal, interpretive, and applied engagements in a progressive ramping 
approach and we will base these examples in a hypothetical course assignment relating to obesity.

Let us imagine that a student is cleared and ready for a return to learn. This does not mean that the student can return to the same intensity of pace, time and attention she was engaging in before her concussion simply because she has been given medical clearance. Let us extend our imagining exercise and imagine that this student is in a class that has an assignment that requires her to work in a group and design a physical training program for a person diagnosed as obese. She and her group mates were at the beginning stages of this assignment when she was diagnosed with a concussion. Several weeks have passed and she has been cleared to return to class. What might the instructor do to ease this student back into a manageable pace and intensity of work? Some strategies could be applied to the learning environments, both actual and virtual. These include:

1. Avoid an online environment when possible, by providing other sources of information about, and for, the course work.

2. Minimize the extraneous stimuli in the room or space where the student does the learning tasks and in the instructions associated with the tasks.

3. Allow for self-paced timing on the tasks.

4. Use tactile and kinesthetic pathways of processing as well as visual and auditory, to minimize stress on the most affected system (often the visual system).

5. Allow for self-paced breaks from stimuli and processing.

We propose that instructors seriously consider facilitating re-engagement with learning using a progression of literal, to interpretive, to applied tasks related to the purpose of the assignment. In this model, literal tasks are unmediated, and involve mostly concrete engagement with the subject matter, e.g. "Find the definition of obesity on page 6." Interpretive tasks require the use of a theory, model or principle to guide reasoning, e.g. "Compare the mental and physical health risks of obesity." Applied tasks call for the transfer of learning from one context to another, e.g. "Explain, and give examples of, fat shaming." Below you will see a series of suggested learning tasks associated with the hypothetical assignment that illustrate how to work with literal, interpretive and applied construction and phrasing.

\section{Sample Assignment}

Assignment: Programming for a Client Managing Obesity

Challenge: student returning to class after a medical absence necessitated by concussion

\section{Literal Learning Tasks}

1. Re-read the description of the assignment, or have a classmate read it to you and then you list the different components that must be done to complete the assignment.

2. Do a conversation check in with the other members of your group about obesity and write down one point from each person that you think is important.

3. Use 10 post it notes and write down five risks and five benefits of a training program for a person who is managing obesity; put the post it notes on a piece of flip chart paper so you can continue to add other points as you think of them.

4. Find five images of people who would meet the criteria of obesity doing physical activity.

5. Go to the place where you usually work out. Walk around the space three times and count the number of people who would meet the criteria of obesity.

The verbs that construct the tasks in the above activities allow the student to engage in literallevel, knowledge-based thinking and writing. As discussed earlier in the paper, they are at the 
most progressively simple level, yet they still allow the student to participate with her peers and re-engage with the course assignment and material.

\section{Interpretive Learning Tasks}

1. List the criteria for obesity and then rank the criteria in terms of a) health and safety, and b) dignity and shame.

2. Choose three pieces of equipment for training a person managing obesity and describe how you could use the equipment in three different ways (or three different activities) that would be appropriate for a person managing obesity who is at the beginning stages of a training program (This could also be done for a person in the middle and near the end of a training cycle).

3. With your group, take turns in a discussion circle and design a progression for a cardio activity; use post-it notes so you can move the elements around to make the progression go from simple to complex.

4. Have a discussion with your group about the concept of "fat shaming" and develop some strategies for recognizing it and addressing it.

At this level, you will note that the tasks have become more process-oriented and involve combining a literal task with a more comprehension-based, interpretive engagement with the material and with group members. This is in contrast with the concrete, product-oriented responses required in a literal task (Kolb, 1984). For this interpretive type of task, instructors would use verbs such as explain, confirm, infer, relate, paraphrase, describe, discuss. These activities are at a more complex level of thinking and problem solving. The student can engage in a deeper kind of thinking and can contribute more to the group's assignment.

\section{Applied Learning Tasks}

1. Describe five training activities that would be contraindicated for a person managing obesity and explain why they would be contraindicated.

2. Describe how you would adapt the activities you described above so that they no longer pose an injury or safety risk.

3. Select two flexibility activities that would stretch what you consider to be the three most important muscle groups; write a script for how you would present these to your client.

4. Do a survey of your training space and rate the equipment and layout in terms of its adaptability, versatility and safety for persons managing obesity.

In these examples, you will note again the linking of a previous, interpretive-type task with a follow up application task, one that requires more in-depth problem solving, more combinatory writing and a consideration of more factors associated with the assignment and the group's functioning. Here, instructors would use verbs such as modify, build, construct, produce, solve, report, diagram, forecast. Instructors will hopefully see a progressive improvement in the student's ability to stay focused longer, and to work at a level that approximates many of the demands of the course assignment.

Our work on concussion and its effects on learning and in various learning contexts has compelled us to explore somewhat unconventional problem-solving options for our pedagogy and course design. We have used principles of universal instructional design (Tobin, 2014), research on learning in higher education (Entwistle, Tait, \& McCune, 2000), and the work of liberatory pedagogy theorists (Finlay \& Faith, 1987; Zimmett, 1987) to inform how we adapt our alignment elements (content, assessment, pedagogy), our learning environments, our assignments, and our task phrasing in the service of progressive return to learn for students recovering 
from concussion. One significant insight, over and above the veracity of thoughtfully planned and implemented progressions in learning, is that all learners benefit from a progressive approach to task phrasing and a ramping into a course from a simple to a more complex approach to difficulty, pace, and complexity. This means that the adaptations made for students needing them can be of benefit for any student. The dignity and safety of students requiring adaptations and accommodations as well as the overall learning of all the students in the class can be protected and honored. Further, the use of progressive tasks and careful task phrasing in instruction can be helpful for both novice and experienced teachers in post-secondary contexts as they continue to encounter increasingly diverse learners and increasingly complex scenarios in higher education.

Finally, it may be the case that a student's symptoms do not improve within the 12-15 weeks of the semester, and that, regardless of the adaptations made in progression and ramping, their learning cannot be reset to pre-concussion levels at a pace that allows them to complete the course successfully. In this case, an instructor can and should work with the student and school administration to support their withdrawal from the course with dignity and safety. For example, it may be possible to provide her with a back-dated (if necessary) withdrawal to avoid a financial penalty.

We have provided examples of strategies that can assist instructors with supporting students returning to learn after concussion and we have shown how to construct and phrase learning tasks from a literal to an applied level of engagement (and difficulty). While we have chosen subject matter that is typical of our own discipline, we hope that the examples provide a template for others who are concerned and committed to progressive and safe practices in higher education for students who are returning to learn after concussion.

\section{References}

An educator's guide to concussions in the classroom. (2018, September 29). Retrieved from https://www.nationwidechildrens.org/spec ialties/concussion-clinic/concussiontoolkit/an-educators-guide-to-concussionsin-the-classroom

Barkhoudarian, G., Hovda, D., \& Giza, C. (2011). The molecular pathophysiology of concussive brain injury. Clinics in Sports Medicine, 30(1), 33-48. doi:10.1016/j.csm.2010.09.001

Bloom's Taxonomy verb wheel. (2018, June 20). Retrieved from https://sites.google.com/site/bloomstaxon omy2/verb-wheel

Centers for Disease Control and Prevention. (2019, January 29). TBI: get the facts. Retrieved from https://www.cdc.gov/traumaticbraininjury /get_the_facts.html

Entwistle, N., Tait, H. \& McCune, V. (2000). Patterns of response to an approaches to studying inventory across contrasting groups and contexts. European Journal of Psychology of Education, XV(1), 33-48.

Finlay, L. S., \& Faith, V. (1987). Illiteracy and alienation in American colleges: Is Paulo Freire's pedagogy relevant? In I. Shor (Ed.) Freire for the classroom: A source book for liberatory pedagogy (pp. 63-85). Portsmouth, NH: Boynton Cook Publishers.

Freire, P. (1972). Pedagogy of the oppressed. New York: Herder and Herder.

Frost, G., \& Connolly, M. (2018). Managing the transition from concussion to return to learn in postsecondary education: strategies based on principles of UDL. In J. Eikenaar (Ed.) Collected Essays in Learning and Teaching, (Vol. 11, pp. 109-117). Ottawa, ON: Society for Teaching and Learning in Higher Education. Henry, L., Elbin, R., Collins, M., Marchetti, G., \& Kontos, A. (2016). Examining recovery 
trajectories following sport-related concussion using a multi-modal clinical assessment approach. Neurosurgery, 78(2), 232-241.

doi:10.1227/NEU.0000000000001041

Hutchinson, M., Comper, P., Csenge, G., \& Richards, D. (2014). Psychosocial and psychological factors related to delayed recovery from concussion in high school students. British Journal of Sports Medicine, 48(7), 136. Abstracts from the IOC World Conference on Prevention of Injury \& Illness in Sport, Monaco 2014, 136. doi: 10.1136/bjsports-2014-093494.136

Keightley, M., Sing Saluja, R., Chen, J. K., Gagnon, I., Leonard, G., Petrides, M., \& Ptito, A. (2014). A functional magnetic resonance imaging study of working memory in youth after sport-related concussion: is it still working? Journal of Neurotrauma, 31, 437-451. doi: 10.1089/neu.2013.3052

Kolb, D. A. (1984). Experiential learning: Experience as the source of learning and development. Englewood Cliffs, N.J.: Prentice Hall.

McCrory, P., Meeuwisse, W., Dvořák, J., Aubry, M., Bailes, J., Broglio, S.,... Vos, P. (2017). Consensus statement on concussion in sport - the 5th international conference on concussion in sport held in Berlin, October 2016. British Journal of Sports Medicine, 51, 838-847. doi: 10.1136/bjsports-2017097699

Ontario Human Rights Commission. (2019, January 29). Accommodating students with disabilities Roles and responsibilities (fact sheet). Retrieved from http://www.ohrc.on.ca/en/accommodatin g-students-disabilities-roles-andresponsibilities-fact-sheet

Sady, M., Vaughn, C., \& Gioia, G. (2011). School and the concussed youth - recommendations for concussion education and management. Physical Medicine and Rehabilitation Clinics of North America, 22(4), 701-719. doi: 10.1016/j.pmr.2011.08.008
Tobin, T.J. (2014). Increase online student retention with universal design for learning. The Quarterly Review of Distance Education, 15(3), 13-24.

Valovich McLeod, T \& Gioia, G. (2010). Cognitive rest: the often neglected aspect of concussion management. Athletic Therapy Today, 15(2), 1-3,

Zimmett, L. (1987). More than basics: Teaching critical reading in high school. In Ira Shor (Ed.) Freire for the classroom: A sourcebook for liberatory teaching (pp.122-128). Portsmouth, NH: Boynton Cook Publishers.

\section{Biographies}

Dr. Gail Frost is an associate professor in the Department of Kinesiology at Brock University. She teaches courses in functional anatomy, injury prevention and care, and therapeutic exercise and is committed to finding effective ways to help students learn.

Dr. Maureen Connolly is a Professor of Physical Education and Kinesiology at Brock University. Maureen's teaching and research interests include curriculum, stressed embodiment, dance and movement education, and Freirian approaches to teaching and learning. 